\title{
A Study on the Effect of Alcoholism on the Family Members of Alcoholic Patients
}

\author{
Manokaran Chinnusamy ${ }^{1}$ Priscilla Rubavathy Eugin ${ }^{1} \quad$ Sathiyanarayanan Janakiraman ${ }^{1}$ \\ ${ }^{1}$ Department of General Medicine, Sri Manakula Vinayagar Medical \\ College and Hospital, Kalitheerthalkuppam, Madagadipet, \\ Pondicherry, India \\ Address for correspondence Manokaran Chinnusamy, MBBS, MD, \\ 9, Associate Professor Quarters, Sri Manakula Vinayagar Medical \\ College and Hospital Campus, Kalitheerthalkuppam, Madagadipet, \\ Pondicherry 605107, India (e-mail: manokaran.smvmch@gmail.com).
}

J Health Allied Sci ${ }^{\mathrm{NU}}: 2021 ; 11: 66-72$

\begin{abstract}
Keywords

- alcoholism

- alcoholism and family relationship

- impact of alcoholism
\end{abstract}

Introduction Alcohol use disorder is commonly known as "alcoholism" but is also known as a family disorder, not because it runs in families but because it tends to impact the family members more than just the individual. Alcoholism is one of the leading causes of marital problems, divorce, domestic violence, child abuse and neglect, and strained relationships between the partners and also between the parent and child. The per capita alcohol consumption has increased from $2.2 \mathrm{~L}$ (2005) to $2.7 \mathrm{~L}$ (2016) and is expected to increase by another $2.2 \mathrm{~L}$ by 2025 . According to the World Health Organization, $55 \%$ of domestic violence is related to alcohol abuse by the partner. This study aims to identify the impact of alcoholism on the individual's health as well as the family members depending on the level of alcohol dependence.

Materials and Methods A cross-sectional study was conducted among patients admitted in the ward with a history of alcohol intake. AUDIT-C (Alcohol Use Disorders Identification Test-C) questionnaire was used to detect dependence and also a structured questionnaire was used to gather information regarding the financial and psychological well-being of the family from the family member accompanying the person. Other parameters of the patient were also considered such as liver function test, abdomen ultrasonography, and upper gastrointestinal endoscopy, wherever available.

Results A total of 100 patients were included in the study; 59 patients were admitted due to various reasons secondary to alcohol intake. A score of $>4$ was suggestive of alcohol dependence: $73 \%$ (73) of the participants had a score of $>4 ; 65 \%$ of the participants' family members gave a positive history of impaired interpersonal relationships; $45 \%$ gave a positive history of battering; and $69 \%$ had mental health issues such as depression, lack of confidence, inferiority complex, and decreased sleep. Also, $51 \%$ (51) gave a positive history of financial contribution by the participant toward the family expenses.

Conclusion The study shows that the problems of alcohol abuse have been associated with increased suffering to the family members, which contributes to a high level of interpersonal conflict, domestic violence, financial difficulties, and psychological disturbances, along with increasing the risk of developing comorbidities associated with alcohol abuse by the individual, which further adds to burden of the family. published online January 7, 2021
DOI https://doi.org/

$10.1055 / \mathrm{s}-0040-1722426$ ISSN 2582-4287. (c) 2020. Nitte (Deemed to be University).

This is an open access article published by Thieme under the terms of the Creative Commons Attribution-NonDerivative-NonCommercial-License, permitting copying and reproduction so long as the original work is given appropriate credit. Contents may not be used for commercial purposes, or adapted, remixed, transformed or built upon. (https://creativecommons.org/licenses/by-nc-nd/4.0/).

Thieme Medical and Scientific Publishers Pvt. Ltd. A-12, 2nd Floor, Sector 2, Noida-201301 UP, India 


\section{Introduction}

Alcoholism is defined as a diseased condition due to the excessive use of alcoholic beverages. According to the American Psychiatric Association, the three criteria for diagnosis of alcoholism includes: (1) hand tremors and blackouts, (2) obsessive desire to drink, and (3) behavioral problems affecting work life. ${ }^{1}$ Alcohol dependence syndrome is defined as "a cluster of physiological, behavioural and cognitive phenomena in which the use of a substance takes a higher priority for a given individual than other behaviours that had great value." 1

Alcoholics may belong to any age group, background, income level, and social or ethnic group. Alcoholism not only affects the individual but also the family. Hence it may also be known as a family disease. It disrupts family life and causes harmful effects on the members, which last for a lifetime. Each member of the family is affected differently, especially the spouse and the children. The spouse suffers from feeling of hatred, self-pity, avoidance of social contacts, and may suffer exhaustion and become mentally and physically ill. Many children of the alcoholics suffer from low self-esteem, loneliness, helplessness, fear, guilt, and severe depression. Alcoholism is also associated with crime and violence, which reflects as incest and battering in the family. $^{2}$

According to the Diagnostic and Statistical Manual of Mental Disorders, 5th Edition, the diagnosis of alcohol use disorder can be made if 2 or more out of the 11 criteria are fulfilled, occurring at any time in the same 12-month period. Severity of alcohol use disorder is based on the number of criteria fulfilled: (1) Mild, two or three criterions, (2) Moderate, four or five criterions, and (3) Severe, six or more of the criterion items. ${ }^{3}$

One standard alcohol drink roughly contains $14 \mathrm{~g}$ of pure alcohol as per United States Guidelines. The amount of alcohol content varies in each beverage. In India, the pure ethanol concentration in various drinks available are as follows: beer, $5 \%(355 \mathrm{~mL})$; strong beer, $8 \%(240 \mathrm{~mL})$; wine, 12 to $15 \%$ (150 mL); foreign liquor or Indian manufactured foreign liquor, $42.8 \%$ (43 mL); and country liquor, 40 to $70 \%(45 \mathrm{~mL})$. The different measures used in India are: peg, 40 to $60 \mathrm{~mL}$; pint, 330 to $375 \mathrm{~mL}$; and quarter, $180 \mathrm{~mL}^{4}$

Alcohol use disorder commonly known as "alcoholism" is also known as a family disorder, not because it runs in families but because it tends to impact the family members more than just the individual. Alcohol is one of the leading causes of marital problems, divorce, domestic violence, child abuse and neglect, and strained relationships between the partners and also between the parent and child. The per capita alcohol consumption has increased from $2.2 \mathrm{~L}$ (2005) to $2.7 \mathrm{~L}$ (2016) and is expected to increase by another 2.2 L by 2025. According to the World Health Organization (WHO), 55\% of domestic violence is related to alcohol abuse by the partner. Both the spouse and the children of the individuals are psychologically impacted.

\section{Materials and Methods}

\section{Aim and Objective}

The aim of the study was to identify the impact of alcoholism on the family members of the alcoholic patients with regard to various aspects such as mental health, domestic violence, interpersonal relationships, and financial burden on the family.

\section{Study Design}

Hospital-based cross-sectional study was conducted at a tertiary health-care setup of Sri Manakula Vinayagar Medical College located at Kalitheerthalkuppam in Pondicherry, which is on the outskirts on the way to Villupuram. Due to the reduced tax on alcohol in Pondicherry, the prevalence is comparatively higher. We get patients from the neighboring villages in Tamil Nadu also.

\section{Study Patients}

All adult patients between the age of 20 and 60 years admitted in ward and attending the outpatient department, with history suggestive of alcohol use disorder, under the department of General Medicine, were studied for a period of 6 months. By systematic sampling, 100 patients were selected for the study.

\section{Methodology}

After obtaining informed written consent from the patients, routine history and physical examination of the individual was done. Using Alcohol Use Disorders Identification Test-C (AUDIT-C) questionnaire, ${ }^{5}$ alcohol dependence was identified in the participant. Another structured questionnaire was used to detect the impact on the psychological aspect, domestic violence, interpersonal relationships, and financial burden in the family, from the spouse or the family member accompanying the person. Other variables included in the study were: socio-demographic variables, laboratory parameters, abdomen ultrasonography (USG), and upper gastrointestinal endoscopy (UGIscopy).

\section{Statistical Analysis}

Data entry and analysis were done using Epi Info (version 3.5.4) and SPSS version 24 software. Descriptive statistics were calculated for background variables and the prevalence of alcoholism. Chi-square test and $p$-value were calculated to look for the significance of the association between alcoholism and social factors.

\section{Results}

A total of 100 patients were included in the study: $36 \%$ of the patients were in the range of 31 to 40 years and 24\% in the range 41 to 50 years, which includes the major earning population in our society (- Table 1).

Considering the years of alcohol consumption, $51 \%$ of the population were consuming alcohol for 1 to 10 years and $36 \%$ between 11 and 20 years (-Fig. 1). 
Table 1 Distribution of patients based on their age

\begin{tabular}{|l|l|l|}
\hline Age (in years) & Number & Frequency (\%) \\
\hline $21-30$ & 9 & 9 \\
\hline $31-40$ & 36 & 36 \\
\hline $41-50$ & 24 & 24 \\
\hline $51-60$ & 20 & 20 \\
\hline $61-70$ & 9 & 9 \\
\hline $71-80$ & 2 & 2 \\
\hline
\end{tabular}

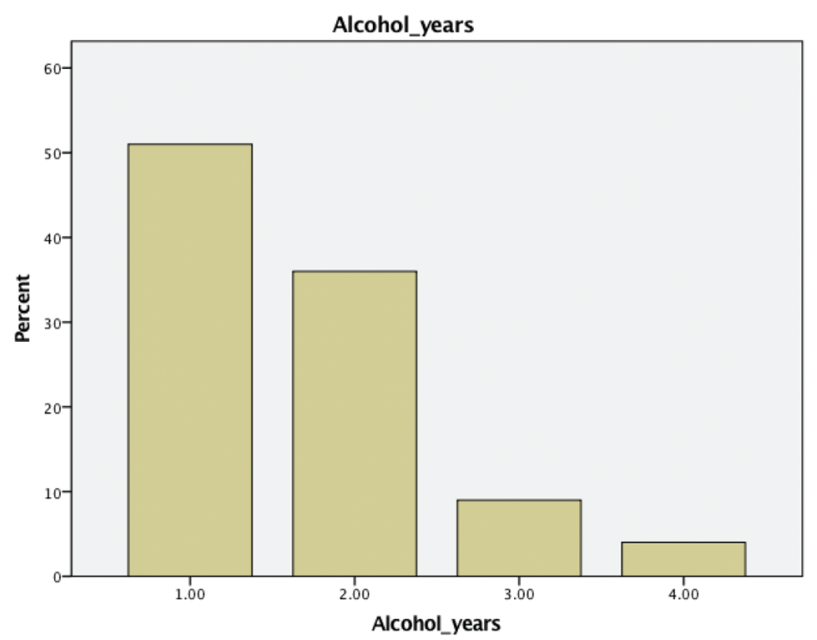

Fig. 1 Years of alcohol consumption.

Among the patients, 59\% (59) had associated smoking habit, which is also one of the major risk factors for various health-related issues.

The prevalence of comorbidities among the patients was studied. Thus, 72 patients did not have any comorbidity while 19 patients had type 2 diabetes mellitus, out of which 10 patients had only type 2 diabetes mellitus and 9 patients had both type 2 diabetes mellitus and systemic hypertension. A total of 12 patients had systemic hypertension, 3 patients had previous history of cerebrovascular accident, and 1 patient had a history of coronary artery disease. Also, three patients were found to be positive for hepatitis B infection, one patient had chronic calcified pancreatitis, one patient had bronchial asthma, and another one patient had epilepsy (-Table 2).

Among the 100 patients, 59 patients were admitted due to various reasons secondary to alcohol intake, either as a direct or indirect influence such as alcoholic gastritis, alcohol withdrawal seizure, alcohol withdrawal symptoms, hypokalemia, alcoholic liver disease, alcohol-induced pancreatitis, alcoholic hepatitis, cerebrovascular accident, and ingestion of poison following alcohol intake. The remaining 41 patients were admitted due to other causes such as febrile illness, accelerated hypertension, uncontrolled blood sugars, coronary artery disease, chronic kidney disease.

Various laboratory parameters such as serum bilirubin levels, liver enzymes, abdomen USG, and UGIscopy were studied among the patients with the available data.
Table 2 Distribution of the comorbidities among the patients

\begin{tabular}{|l|l|}
\hline Comorbidities & Frequency \\
\hline No comorbidities & 72 \\
\hline Type-2 diabetes mellitus & 19 (only T2DM, 10) \\
\hline Systemic hypertension & $\begin{array}{l}12 \text { (T2DM with systemic } \\
\text { hypertension, 9) }\end{array}$ \\
\hline Coronary artery disease & 1 (with T2DM) \\
\hline Cerebrovascular accident & $\begin{array}{l}3 \text { (with T2DM, 1; with both T2DM } \\
\text { and SHTN, 1) }\end{array}$ \\
\hline Pancreatitis & 1 \\
\hline Chronic kidney disease & 1 \\
\hline Hepatitis B infection & 3 (with SHTN, 1) \\
\hline Bronchial asthma & 1 \\
\hline Seizure & 1 \\
\hline
\end{tabular}

Abbreviations: T2DM, type-2 diabetes mellitus; SHTN, systemic hypertension.

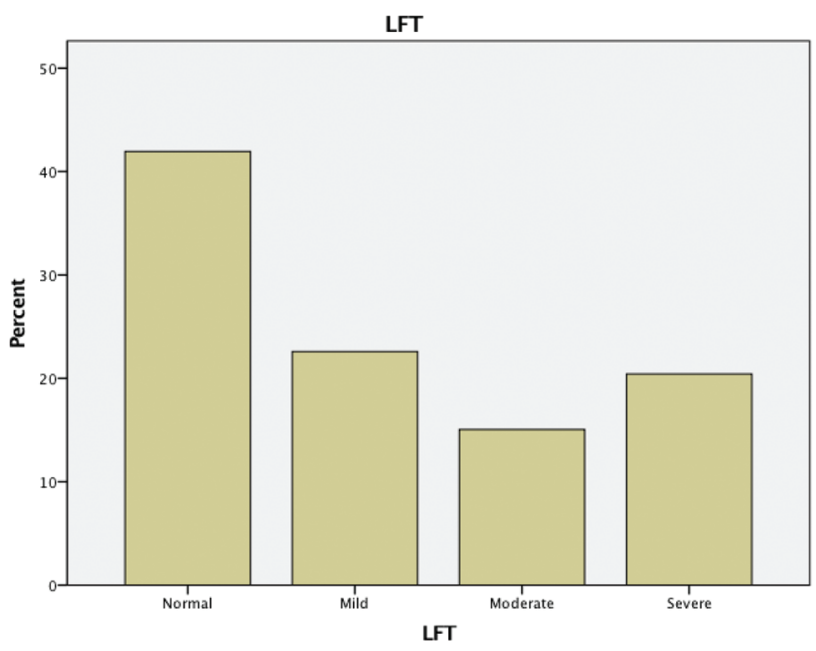

Fig. 2 Serum bilirubin levels.

Serum bilirubin levels were available for 93 patients among the 100 patients, out of which $41.9 \%$ (39) patients were found to be normal. Serum bilirubin levels were further divided into mild (1.0-1.5 mg/dL), moderate (1.5-3.0 mg/dL), and severe $(3.0-10 \mathrm{mg} / \mathrm{dL})$. Also, 22.6\% (21) patients had mild derangement, $15.1 \%$ (14) had moderate derangement, and 20.4\% (19) had severe derangement (-Fig. 2).

Liver enzymes were available for 93 patients, out of which $24.7 \%$ (23) patients were in the range 30 to $100 \mathrm{IU} / \mathrm{L}$, $52.7 \%$ (49) patients in the range 101 to $300 \mathrm{IU} / \mathrm{L}$, and $15.1 \%$ (14) patients in the range 301 to $500 \mathrm{IU} / \mathrm{L}$ (-Fig. 3).

Abdomen USG was done for 40 patients, out of which $10 \%$ (4) of patients had normal liver, $32.5 \%$ (13) patients had fatty liver, 30\% (12) had ascites, $22.5 \%$ (9) had cirrhosis, $2.5 \%$ (1) had renal calculi, and 2.5\% (1) had chronic calcific pancreatitis (-Table 3 ).

UGIscopy was done for 11 patients among which $72.7 \%$ (8) had grade I small esophageal varices, 9.1\% (1) had grade II medium esophageal varices, and 18.2\% (2) had grade III large esophageal varices ( - Table 4 ). 
The impact of alcoholism among family members was studied with regard to different aspects such as family disputes, financial contribution by the participant, battering, and mental health of the spouse using a questionnaire. Patient history was obtained from the family member accompanying the participant, predominantly the spouse.

Based on the questionnaire, 65\% (65) of the patients' family members gave a positive history of impaired interpersonal

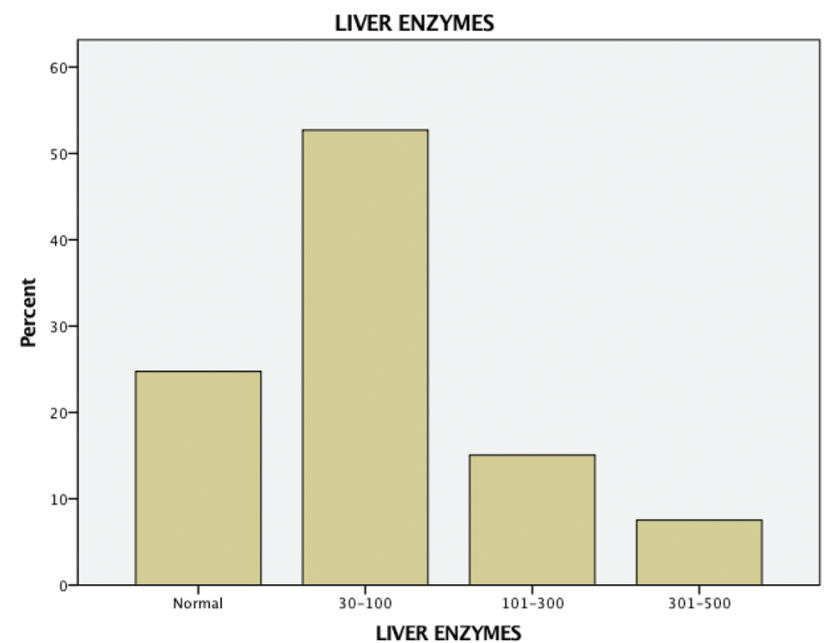

Fig. 3 Liver enzyme levels.

Table 3 Distribution of patients based on their USG findings

\begin{tabular}{|l|l|l|}
\hline USG finding & Frequency & Percent (\%) \\
\hline Normal & 4 & 10 \\
\hline Fatty liver & 13 & 32.5 \\
\hline Ascites & 12 & 30 \\
\hline Cirrhosis & 9 & 22.5 \\
\hline Renal calculi & 1 & 2.5 \\
\hline $\begin{array}{l}\text { Chronic calcific } \\
\text { pancreatitis }\end{array}$ & 1 & 2.5 \\
\hline
\end{tabular}

Abbreviation: USG, ultrasonography.

Table 4 Distribution of patients based on their UGIscopy findings

\begin{tabular}{|l|l|l|}
\hline UGIscopy findings & Frequency & Percent (\%) \\
\hline Grade I small esophageal varices & 8 & 72.7 \\
\hline Grade II medium esophageal varices & 1 & 9.1 \\
\hline Grade III large esophageal varices & 2 & 18.2 \\
\hline
\end{tabular}

Abbreviation: UGlscopy, upper gastrointestinal endoscopy. relationship, 45\% (45) gave a positive history of battering, and 69\% (69) had mental health issues such as depression, lack of confidence, inferiority complex, and decreased sleep. Also, 51\% (51) gave a positive history of financial contribution by the participant toward the family expenses ( $\mathbf{- T a b l e ~} \mathbf{5}$ ).

Prevalence of alcohol dependence among the patients was studied using the AUDIT-C questionnaire. A score of $>4$ was suggestive of alcohol dependence: $73 \%$ (73) of the patients had a score of $>4$ ( - Fig. 4 ).

Association between the degree of alcohol dependence based on the AUDIT-C score and the impact on family members was studied ( $\mathbf{- T a b l e ~} \mathbf{6}$ ).

Among the 27 patients scoring 1 to 4,5 patients had family disputes, 4 had history of battering, 7 had history of disturbed mental health among family members, and 16 patients financially supported the family.

Among the 23 patients in score range 5 to 6,18 patients had family disputes, 11 had history of battering, 18 had disturbed mental health among family members, and 14 patients financially supported the family.

Among the 41 patients in score range 7 to 8,36 patients had family disputes and 26 had history of battering; 36 participants' family members had disturbed mental health and 15 patients financially contributed for the family.

Among the nine members with a score of $>9$, six patients had family disputes, four had history of battering, eight patients' family members had disturbed mental health, and six patients supported their families financially.

- Table 7 shows that the association between alcohol dependence and family disputes, including battering and

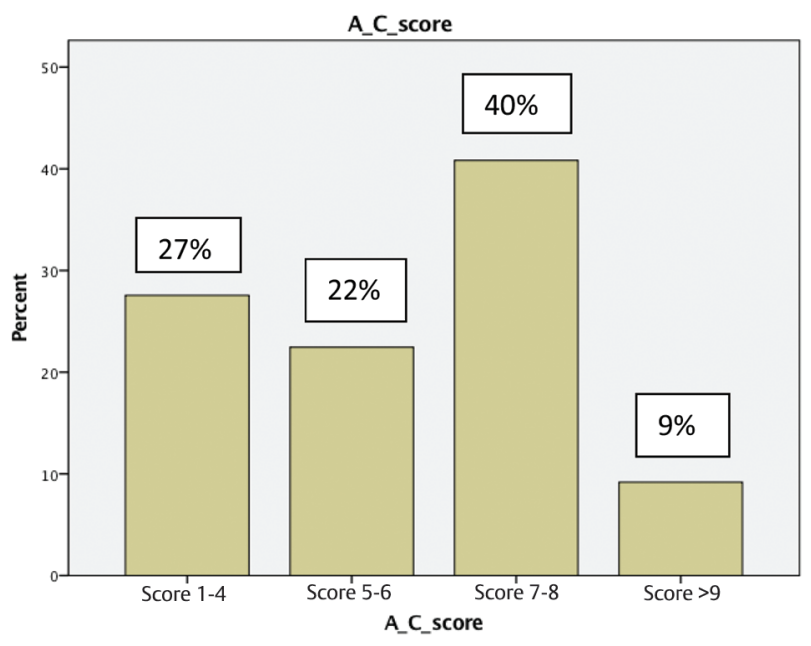

Fig. 4 AUDIT-C (Alcohol Use Disorders Identification Test) score.

Table 5 Distribution of patients based on the impact of alcoholism on the family

\begin{tabular}{|l|l|l|l|l|}
\hline Family impact & Yes & Percent (\%) & Frequency & Percent (\%) \\
\hline & Frequency & 65 & 35 & 35 \\
\hline Family disputes & 65 & 45 & 55 & 55 \\
\hline Battering & 45 & 69 & 31 & 31 \\
\hline Mental health & 69 & 51 & 49 & 49 \\
\hline Financial contribution & 51 & & \\
\hline
\end{tabular}


Table 6 Association between the AUDIT-C score and impact of alcoholism on family

\begin{tabular}{|c|c|c|c|c|c|c|c|c|c|}
\hline \multirow{3}{*}{$\begin{array}{l}\text { Audit-C } \\
\text { score }\end{array}$} & \multicolumn{2}{|c|}{ Family disputes } & \multicolumn{2}{|l|}{ Battering } & \multicolumn{2}{|c|}{ Mental health } & \multicolumn{2}{|c|}{ Financial contribution } & \multirow[t]{3}{*}{ Total } \\
\hline & Yes & No & Yes & No & Yes & No & Yes & No & \\
\hline & \begin{tabular}{|l|} 
Frequency \\
(\%)
\end{tabular} & $\begin{array}{l}\text { Frequency } \\
\text { (\%) }\end{array}$ & $\begin{array}{l}\text { Frequency } \\
\text { (\%) }\end{array}$ & $\begin{array}{l}\text { Frequency } \\
(\%)\end{array}$ & $\begin{array}{l}\text { Frequency } \\
(\%)\end{array}$ & $\begin{array}{l}\text { Frequency } \\
(\%)\end{array}$ & $\begin{array}{l}\text { Frequency } \\
(\%)\end{array}$ & $\begin{array}{l}\text { Frequency } \\
\text { (\%) }\end{array}$ & \\
\hline $1-4$ & 5 & 22 & 4 & 23 & 7 & 20 & 16 & 11 & 27 \\
\hline $5-6$ & 18 & 5 & 11 & 12 & 18 & 5 & 14 & 9 & 23 \\
\hline $7-8$ & 36 & 5 & 26 & 15 & 36 & 5 & 15 & 26 & 41 \\
\hline$>9$ & 6 & 3 & 4 & 5 & 8 & 1 & 6 & 3 & 9 \\
\hline
\end{tabular}

Abbreviation: AUDIT-C, Alcohol Use Disorders Identification Test-C.

Table 7 Significance of the association between the different aspects of impact of alcoholism and AUDIT-C score

\begin{tabular}{|l|l|l|l|l|l|l|}
\hline Audit-C Score & $\mathbf{1 - 4}$ & $\mathbf{5 - 6}$ & $\mathbf{7 - 8}$ & $\mathbf{> 9}$ & $\begin{array}{l}\text { Chi-squared } \\
\text { value }\end{array}$ & $\begin{array}{l}\boldsymbol{p} \text {-Value } \\
(<0.05)\end{array}$ \\
\hline Family disputes & 5 & 18 & 36 & 6 & 36.803 & 0.000 \\
\hline Battering & 4 & 11 & 26 & 4 & 15.633 & 0.001 \\
\hline Mental health & 7 & 18 & 36 & 8 & 32.785 & 0.000 \\
\hline Financial contribution & 16 & 14 & 15 & 6 & 5.926 & 0.115 \\
\hline
\end{tabular}

Abbreviation: AUDIT-C, Alcohol Use Disorders Identification Test-C.

impaired mental health of family members, is statistically significant with $p$-values of 0.000 and $0.001(<0.005)$.

\section{Discussion}

Problems related to alcohol abuse have been associated to different factors, regardless of the causes attributed to this phenomenon. Alcohol consumption and dependence is considered a public health problem and deserves attention because of the social, work, family, physical, legal, and violence-related risks it represents.

Hildebrand et al, in their study published in 2013, say that among young people, as per research, there is a large evidence for the influence of social norms on risky drinking behavior. They proposed a survey instrument that would provide a means to measure individual alcohol-related attitudes and beliefs. ${ }^{6}$

According to the National Mental Health Survey of India 2015 to 16 , the prevalence of alcohol use disorder was $9 \%$ in adult men and alcohol-attributable fraction of all-cause deaths was $5.4 \%$. Out of all the deaths due to liver cirrhosis, $62.9 \%$ were attributed to alcohol use. ${ }^{7}$

In this study using AUDIT-C score it was found that out of the 100 patients, $27 \%$ were not dependent on alcohol whereas $40 \%$ had alcohol dependence with a score of 7 to 8 , and $9 \%$ had a score of $>9$. Similarly, Sujiv et al, in a study conducted in a primary health-care setting in rural Puducherry, found that out of the 256 subjects studied, $39.8 \%$ were found to be current alcohol users and $10.9 \%$ had alcohol use disorder. Based on these findings it was concluded that on screening of alcohol users, for every four users one person was identified to have alcohol use disorder. ${ }^{8}$

A vast majority of the study population hail from Villupuram and Puducherry. According to Kumar et al, the prevalence of alcohol consumption in Villupuram district in 2013 was $16.8 \%$. The age of initiation of drinking was $25+9$ years and $56.2 \%$ had alcohol dependence. ${ }^{9}$ The age distribution among the patients showed that majority of the population belonged to the range of 31 to 40 years (36\%), followed by (24\%) the age group between 41 and 50 years, similar to the observation in the following study. Ramanan and Singh conducted a study on the rural Puducherry and concluded that prevalence of alcohol use among $>18$ years of age was $9.7 \%$ and exclusively among males was $17.1 \%$. The highest prevalence was among 46 to 55 years of age and the residents of joint families. ${ }^{10}$

The reason for consuming alcohol in most of the cases is depression and anxiety. It relieves the symptoms initially to some extent but over the days it worsens the condition and causes depression and anxiety with increased need for alcohol to reduce the symptoms. Chronic use of alcohol increases the risk for suicide, personality disorders, and risk-taking behavior. According to Adityanjee et al, $17.6 \%$ of the psychiatric emergencies were related to alcohol consumption. ${ }^{11}$

Regarding mental health among family members of the alcoholic patients, it was found that $69 \%$ of the caregivers suffered from insomnia, depression, lack of self-confidence, and other such mental health issues. Another study was done to understand the mental health among alcohol users and the following conclusion was given. Brower et al studied 172 men and women receiving treatment for alcohol dependence and found that $61 \%$ of the subjects had symptomatic insomnia. Compared with the patients without insomnia, patients with insomnia frequently reported use of alcohol for sleep and also had more severe alcohol dependence and depression. According to the study, insomnia remained a major predictor of relapse. ${ }^{12}$ In a study by Gururaj and Isaac, the risk of suicide increased 25 times among alcohol users, and among 
women who were the spouse of alcohol abusers it increased by nearly 6 times. ${ }^{13}$

Further in the study by Gururaj and Isaac, it was concluded that the hospital admission rate secondary to alcohol consumption increased by 20 to $30 \%$ because of either direct injury or indirect problems related to alcohol consumption..$^{13}$ Among the 100 patients, 59\% were admitted due to various reasons secondary to alcohol, $20.4 \%$ patients had severe raise of bilirubin levels, $67.8 \%$ had raised liver enzymes more than $300 \mathrm{IU} / \mathrm{L}, 22.5 \%$ had cirrhosis, and $30 \%$ had ascites confirmed by USG. Also, $18.2 \%$ had grade III large esophageal varices. Similarly, Lucey et al, in their article published in 2008, had investigated patterns of use of alcohol and its clinical effects among cirrhotic patients. Heavy drinking was recorded in 25 adrenoleukodystrophy (ALD) subjects but in no non-ALD subjects. In a Cox proportional-hazards model, it was found that only patients with heavy drinking habit on a regular basis were associated with death, while recent heavy drinking led to a huge increase in the risk of variceal hemorrhage. ${ }^{14}$ According to the WHO, the most common complication of long-term alcohol use is alcoholic liver disease. It also states that alcohol consumption increases the risk of breast cancer by 1.4-fold in women and risk of oral and esophageal cancers by threefold and rectal cancers by 1.5 -fold in both genders. ${ }^{1}$

In the study by Gururaj and Isaac, it was found that abuse of the spouse was 2.5 times more common among alcohol abusers: $23.3 \%$ of them physically abused their spouse. ${ }^{13}$ Similarly in the current study, $65 \%$ of the study population had family disputes and $45 \%$ had a history of battering. Also, the study by Ramanan and Singh states that half of the patients had strained relationship with family members, especially spouse and children, and also with neighbors. ${ }^{10}$ According to Benegal et al, alcohol-dependent persons spent more money than they earned and around $60 \%$ of the families were supported by other family members. ${ }^{15}$ In this study, $51 \%$ of the patients financially contributed for the family needs.

The majority had alcohol dependence problems and about one-fifth had chronic health problems, diabetes mellitus, and hypertension. ${ }^{10}$ Similarly, in the current study 19 patients had diabetes and 12 patients had systemic hypertension. The various health problems associated with alcohol intake include gastritis, alcoholic liver disease, cirrhosis, and risk of cancers such as oral cavity, pharynx, esophagus, and larynx. ${ }^{16}$ It also leads to infertility and high-risk sexual behaviors, and predisposes to infections such as HIV and Hepatitis-B. ${ }^{17}$ Other effects include loss of bone mineral density, myopathy impaired memory, alcoholic tremors, Wernicke's encephalopathy, and cerebellar degeneration. ${ }^{18}$

Dutta et al, in their study conducted in rural Tamil Nadu, have found that the prevalence of alcoholism among the study patients was $35.7 \%$. Among them, $4.5 \%$ presented with symptoms of alcoholism and had taken treatment. Reason for not taking treatment for alcoholism among study population was mainly due to their family problems (55.2\%). ${ }^{19}$

Grant et al, in their study, found a lifetime alcohol use disorder prevalence of $29.1 \%$ and a 12 -month prevalence of $13.9 \%$. This represents $~ 68.5$ million and 32.6 million adult population, respectively. ${ }^{20}$

The study by Esser et al states that among the studies from lower- and middle-income countries, in a household survey from five states in India, $43.2 \%$ of adult male respondents reported at least one alcohol-related harm (physical and psychological abuse and neglect) to children in their homes, in the past year. ${ }^{21}$

\section{Conclusion}

The study shows that the problems of alcohol abuse have been associated with increased suffering to the family members, which contributes to a high level of interpersonal conflict, domestic violence, financial difficulties, and psychological disturbances, along with increasing the risk of developing comorbidities associated with alcohol abuse by the individual, which further adds to burden of the family.

Alcoholism is an emerging major health problem in India. Hence it is necessary to educate the society about the consequences of chronic alcoholism through various health education programs. It can further be controlled by effective control policies on alcohol production, taxation, and promotion, and by introduction of programs to help the individuals with addiction as well as their family members where they can seek help by enrolling in de-addiction programs similar to the Community Reinforcement And Family Training (CRAFT) for engaging unmotivated drug users in treatment and ARISE methods functioning in other countries.

\section{Conflict of Interest}

None declared.

\section{Acknowledgment}

The authors acknowledge the Epidemiology Unit of Community Medicine for their technical support and specially thank the entire team for their help.

\section{References}

1 World Health Organization. Regional Office for South-East Asia. Prevention of harm from alcohol use. http://apapaonline. org/data/Regional_Data/SEARO/Alcohol_Facts_and_Figures. pdf. Accessed July 26, 2018.

2 Parsons T. Alcoholism and its effect on the family. All Psych J 2003;14

3 Jameson JL, Harrison's Principles of Internal Medicine. New York: McGraw-Hill Education; 2018

4 Nayak MB, Kerr W, Greenfield TK, Pillai A. Not all drinks are created equal: implications for alcohol assessment in India. Alcohol Alcohol 2008;43(6):713-718

5 Fagbemi K. Q: What is the best questionnaire to screen for alcohol use disorder in an office practice? Cleve Clin J Med 2011;78(10):649-651

6 Hildebrand J, Maycock B, Burns S, et al. Design of an instrument to measure alcohol-related psychosocial influences in the development of norms among 13-year-old to 17-year-old adolescents. BMJ Open 2013;3(8):e003571

7 World Health Organization. Global Health Observatory data repository. Available from: http://apps.who.int/gho/data/ node.main.A1109?lang=en. Accessed Dec 1, 2020 
8 Sujiv A, Chinnakali P, Balajee K, Lakshminarayanan S, 15 Kumar SG, Roy G. Alcohol use and alcohol use disorder among male outpatients in a primary care setting in rural Puducherry. Ind Psychiatry J 2015;24(2):135-139

9 Kumar SG, Premarajan KC, Subitha L. Suguna E, Vinayagamoorthy, Kumar V. Prevalence and pattern of alcohol consumption using alcohol use disorders identification test (AUDIT) in rural Tamil Nadu, India. J Clin Diagn Res 2013;7(8):1637-1639

10 Ramanan VV, Singh SK. A study on alcohol use and its related health and social problems in rural Puducherry, India. J Family Med Prim Care 2016;5(4):804-808

11 Adityanjee MD, Mohan D, Wig NN. Alcohol-related problems in the emergency room of an Indian general hospital. Aust NZ J Psychiatry 1989;23(2):274-278

12 Brower KJ, Aldrich MS, Robinson EA, Zucker RA, Greden JF. Insomnia, self-medication, and relapse to alcoholism. Am J Psychiatry 2001;158(3):399-404

13 . Gururaj G, Isaac MK. Psychiatric epidemiology in India: moving beyond numbers. In: Agarwal SP, ed. Mental Health-An Indian Perspective, 1946-2003. Gurgaon: Elsevier;2004:37-61

14 Lucey MR, Connor JT, Boyer TD, Henderson JM, Rikkers LF; DIVERT Study Group. Alcohol consumption by cirrhotic subjects: patterns of use and effects on liver function. Am J Gastroenterol 2008;103(7):1698-1706
15 Benegal V, Velayudhan A, Jain S. The social cost of alcoholism (Karnataka) Nimhans J 2000;18(1/2):67-76

16 Bagnardi V, Blangiardo $M$, La Vecchia C, Corrao G. A meta-analysis of alcohol drinking and cancer risk. $\mathrm{Br}$ J Cancer 2001;85(11):1700-1705

17 Poulose B, Srinivasan K. High risk behaviours following alcohol use in alcohol dependent men. Indian J Med Res 2009;129(4):376-381

18 Peng MC, Chou WJ, Chen SS. Neurological problems in chronic alcoholics. Gaoxiong yi xue ke xue za zhi=. Kaohsiung J Med Sci 1991;7(8):404-412

19 Dutta R, Gnanasekaran S, Suchithra S, et al. A population based study on alcoholism among adult males in a rural area, Tamil Nadu, India. J Clin Diagn Res 2014;8(6):JC01-JC03

20 Grant BF, Goldstein RB, Saha TD, et al. Epidemiology of DSM-5 alcohol use disorder: results from the National Epidemiologic Survey on Alcohol and Related Conditions III. JAMA Psychiatry 2015;72(8):757-766

21 Esser MB, Rao GN, Gururaj G, et al; Collaborators Group on Epidemiological Study of Patterns and Consequences of Alcohol Misuse in India. Physical abuse, psychological abuse and neglect: evidence of alcohol-related harm to children in five states of India. Drug Alcohol Rev 2016;35(5):530-538 